\title{
Materiales de Aprendizaje Móvil en Contextos Críticos
}

\section{Mobile Learning Material in Critical Contexts}

\begin{abstract}
Resumen
En este trabajo se presenta el sistema mGuías, que surge como respuesta a las necesidades educativas de alumnos afectados por el terremoto que impactó a Chile en Febrero del año 2010. Con este sistema profesores a través del uso de un editor generan guías de trabajo que incluyen apuntes y cuestionarios para sus alumnos y a su vez, los alumnos visualizan y desarrollan estas guías de trabajo en teléfonos celulares. El objetivo de este trabajo fue introducir mGuías y presentar el impacto de las evaluaciones de usabilidad como parte del proceso de desarrollo del sistema mGuías, aportando principalmente en la validación de las funcionalidades y la detección de errores. Los resultados dieron cuenta que el sistema tuvo una muy buena aceptación por parte de profesores y alumnos, y que es una herramienta intuitiva y fácil de usar.

Palabras-clave: Editor de Contenidos. Guías Móviles. Aprendizaje Móvil a través de Celulares.
\end{abstract}

\section{Abstract}

In this work we present the mGuides system that emerges in response to the educational needs of students affected by the earthquake that hit Chile in February 2010. By using this mobile system through an editor, learning guides are generated that include student guides and questionnaires that are visualized and developed through the use of their personal cell phones. The purpose of this work was to introduce mGuides and present the impact of the usability evaluation as part of the development process of mGuides, enriching the process of validation of the functionalities and error detection. The results show that the mGuides system was highly accepted by teachers and learners and that this tool is understandable, usable, intuitive and easy to use. Keywords: Content editor. Mobile Guides. Mobile Learning through Cell Phones.

SÁNCHEZ, Jaime; ESPINOZA, Matías. Materiales de Aprendizaje Móvil en Contextos Críticos. Informática na Educação: teoria \& prática, Porto Alegre, v. 14, n. 2, p. 151-169, jul./ dez. 2011.

\author{
Jaime Sánchez \\ Universidad de Chile \\ Matías Espinoza \\ Universidad de Chile
}

\section{Introducción}

A nte la necesidad de confrontar la falta de infraestructura de salas de clases y en consecuencia el tiempo perdido por los alumnos, producto que el terremoto ocurrido en Chile el 27 de Febrero de 2010, CNN (2010), alteró el normal desarrollo de las actividades en el zona afectada, surgió el sistema mGuías (Guías Móviles) como una solución mientras la situación se normalizaba. El sistema mGuías fue creado como respuesta a las necesidades anteriormente descritas involucrando la participación de profesores y alumnos como usuarios del sistema. La disponibilidad de infraestructura fue un tema crítico, debido a que el terremoto generó la destrucción y también imposibilitó el uso de una serie de colegios y liceos, lo que provocó en algunos casos una reorganización de los recursos disponibles por parte de las autoridades, lo que se reflejó en la redistribución de los alumnos, al juntar distintos establecimientos en un solo lugar y así como también la necesidad de instalar salas de clases de emergencias (ver Figura 1). 

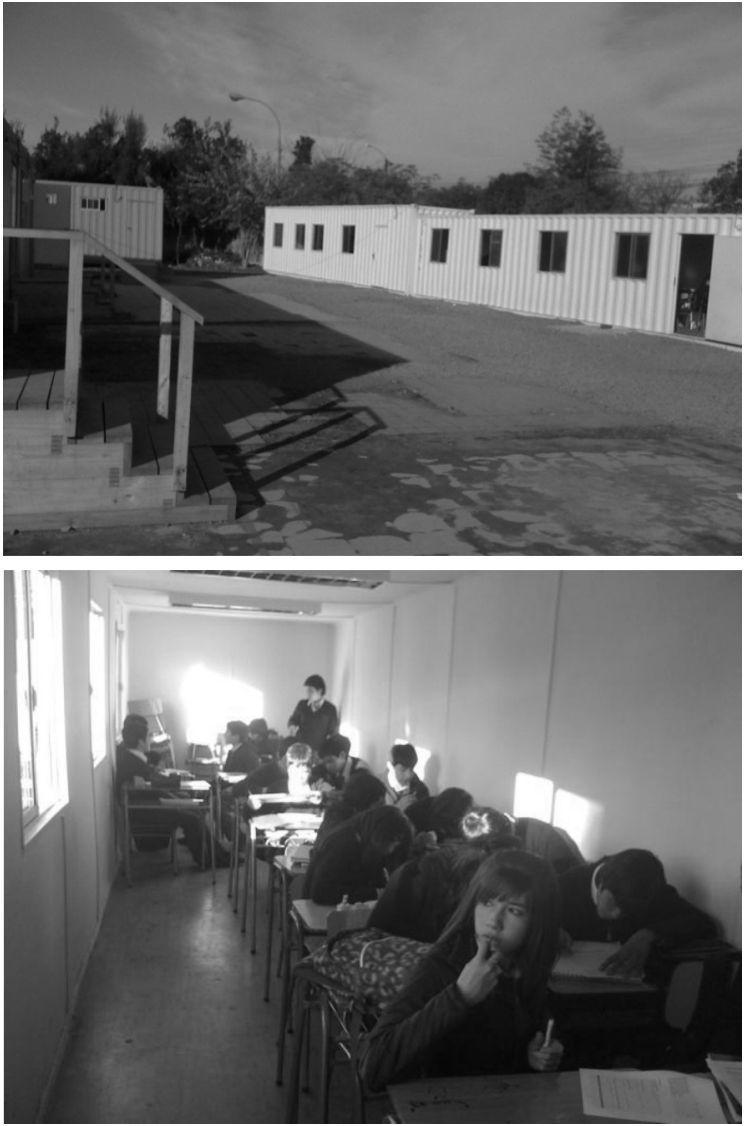

FIGURA 1 - Salas de clases de emergencia instaladas en la ciudad de Talca, una de las zonas más afectadas FONTE: Universidad de Chile

Algunas investigaciones han abordado el tema del potencial pedagógico de los dispositivos móviles (BROWN, 2001, CSETE; WONG; VOGEL, 2004, FACER et al., 2004, JAMES et al., 2003, POWNELL; BAILEY, 2001, WILLIAMS et al., 2005, WILLS, 2001). Este tema se puede estudiar a partir de los usos teóricamente descritos desde quienes diseñan políticas y metodologías de uso, Winograd; Flores (1989), o bien analizando la forma en que los usuarios adoptan e incorporan las tecnologías en sus prácticas cotidianas, Haddon (2001).

Los teléfonos móviles resultaron ser una plataforma atractiva para desarrollar la solu- ción ya que muchos profesores y estudiantes poseen uno de estos dispositivos y porque son dispositivos ligeros y transportables, y además son apropiados para trabajar mientras se camina o bien para ser usados en lugares incómodos, Kangas; Kinnunen (2005). Esto significa que pueden ser utilizados tanto dentro como fuera del aula, aportando al alumno la flexibilidad necesaria para trabajar con una aplicación educativa en cualquier lugar y en cualquier momento. Además, se tuvo que considerar el hecho que los teléfonos móviles tienen limitaciones importantes, Kangas; Kinnunen (2005), tales como la baja capacidad de procesamiento y el tamaño reducido de pantalla, que son aspectos que limitan el tipo de contenidos que el sistema puede soportar y esto invita a los desarrolladores a explorar la mejor forma de presentar los datos, esto último principalmente a través de las evaluaciones de usabilidad.

En la literatura existen aplicaciones que aprovechan las características de los dispositivos móviles para situaciones de emergencia en terreno tales como MobileMap (MONARES et al. 2011), que apoya la toma de decisiones y la colaboración entre bomberos, y otra herramienta que sirve para recolectar y manipular datos de cuidado médico en emergencias, Chittaro, Zuliani y Carchietti (2007). También se han planteado sistemas de e-learning para la simulación de situaciones de emergencia, Taber (2008). La Universidad de Southern en Nueva Orleans planteó un sistema basado en m-learning para continuar el desarrollo de sus actividades luego de la destrucción generada por el Huracán Rita y el Huracán Katrina (OMAR; LIU; KOONG, 2008).

Otros trabajos en la literatura tomados en cuenta como antecedentes para el diseño y desarrollo de mGuías fueron los software BuinZoo y Museo (SÁNCHEZ; MENDOZA; SALINAS, 2009), que son software interac- 
tivos que pueden ejecutarse en dispositivos Pocket PC y Classmate PC. Estos programas consisten en videojuegos basados preguntas de alternativas de quiz, que son respondidas simultáneamente mientras se visita un zoológico y un museo respectivamente. Mobile tourism (KENTERIS; GAVALAS; ECONOMOU, 2009), es un software que permite la creación de contenidos turísticos para dispositivos móviles. Otro trabajo influyente corresponde al motor de videojuegos RPG educativos para teléfonos móviles presentado en Sánchez y Espinoza (2010), el que ha servido de referencia como modo de presentación de información en dispositivos móviles. Desde el enfoque de la edición de contenidos educativos, Mobile Author, Virvou (2004), es una aplicación para teléfonos móviles que ayuda a los profesores a crear y mantener sus recursos educativos en una plataforma virtual, ya que provee un espacio donde los profesores pueden agregar información como clases, pruebas, guías y similares a una base de datos, y donde posteriormente tanto profesores como alumnos pueden acceder al material disponible; toda la comunicación que involucra el uso de este sistema se desarrolla a través de SMS.

El objetivo de este trabajo consistió en introducir mGuías y presentar el impacto de las evaluaciones de usabilidad realizada como parte del proceso de desarrollo del sistema, como mecanismo para la validación de las funcionalidades y la detección de errores. El sistema mGuías fue desarrollado con la finalidad de proveer contenidos, apuntes de aprendizaje, preguntas y cuestionarios móviles para uso con un teléfono celular, con la finalidad de apoyar a aquellos alumnos que no estaban en condiciones de atender clases formales, ya sea por problemas de infraestructura (liceo destruido por el terremoto), de acceso (aislados como consecuencia del sismo) y familiares (casas destruidas).

\section{2 mGuías}

Dado el contexto en el cual se enmarca el desarrollo de este sistema, el diseño de mGuías fue concebido para favorecer la realización de actividades en lugares fuera de la sala de clases dada la falta de infraestructura. De la misma forma, el sistema puede ser utilizado para la realización de actividades dentro de la sala de clases, si el profesor lo estima conveniente. En definitiva, la modalidad de uso dependerá únicamente de la orientación que el profesor integre en las actividades que diseña, a través de las instrucciones para la realización de las mismas y del tipo de contenidos que ingresará en el sistema. En consecuencia, el diseño de la herramienta ofrece libertad tanto para la adopción de una metodología como para uso en algún lugar determinado, con el fin de apoyar actividades de aprendizaje.

Tradicionalmente en el trabajo en la sala de clases, los profesores son los encargados de elaborar y presentar contenidos, gestar actividades y realizar evaluación de las mismas. Por otra parte, los alumnos son quienes reciben los contenidos entregados por los profesores, a través de una presentación oral o bien a través de guías escritas en papel, y luego son también los alumnos los que desarrollan las distintas actividades y evaluaciones elaboradas por los profesores.

El diseño de mGuías sigue una lógica similar. El sistema provee las funcionalidades necesarias para que, por una parte, los profesores puedan generar contenidos de aprendizaje para sus alumnos y cuestionarios con preguntas de alternativas, las cuales pueden funcionar tanto para actividades de entrenamiento, como para actividades de evaluación de conocimientos. Por otra parte, el sistema provee a los alumnos la capacidad de acceder a contenidos y cuestionarios creados por sus profesores 
y desarrollar las actividades relacionadas, en cualquier hora y en cualquier lugar.

En este sentido el sistema mGuías está compuesto por 2 grandes módulos: (1) un editor de proyectos (que en adelante llamamos Editor) para profesores y (2) una aplicación para teléfonos móviles (que en adelante llamamos Motor) para alumnos.

A continuación se describe en detalle la arquitectura, el funcionamiento del sistema, y el desarrollo del editor y del motor. En estos últimos se describen en detalle los prototipos que fueron utilizados más adelante como parte de la evaluación de usabilidad.

\subsection{Arquitectura}

Como se señaló anteriormente, el sistema está compuesto por 2 módulos, un Editor para profesores y un Motor para alumnos.

En términos de hardware el editor está pensado para un uso por parte de los profesores a través de un Computador de escritorio o bien a través de un portátil, ya sea personal o bien uno disponible en el establecimiento donde dicta las clases.

Por otra parte, el motor está pensado para un uso por parte de los alumnos a través de los teléfonos celulares personales.

De acuerdo a los datos conocidos acerca de la proporción entre celulares y personas, en Chile hay más celulares que personas, (EL SIGLO, 2010), indicador que justifica la adopción de esta tecnología como parte del sistema, sumado a las características propias de estos dispositivos que fueron señaladas en la Introducción.

La dificultad principal de realizar aplicaciones para teléfonos móviles es la estandarización de la solución de software. Esto motivó a plantear las siguientes restricciones en términos de los teléfonos móviles a los cuales apuntó la solución: dispositivos que cuentan con un perfil de Java (J2ME) instalado como parte de su sistema y con joystick y teclado como interfaces de ingreso de datos (esto se verá con mayor detalle en la descripción del Motor).

La figura 2 muestra la arquitectura del sistema con sus participantes, profesores y alumnos que interactúan con el editor y motor, a través de las plataformas de hardware respectivas, computador y teléfono celular respectivamente.

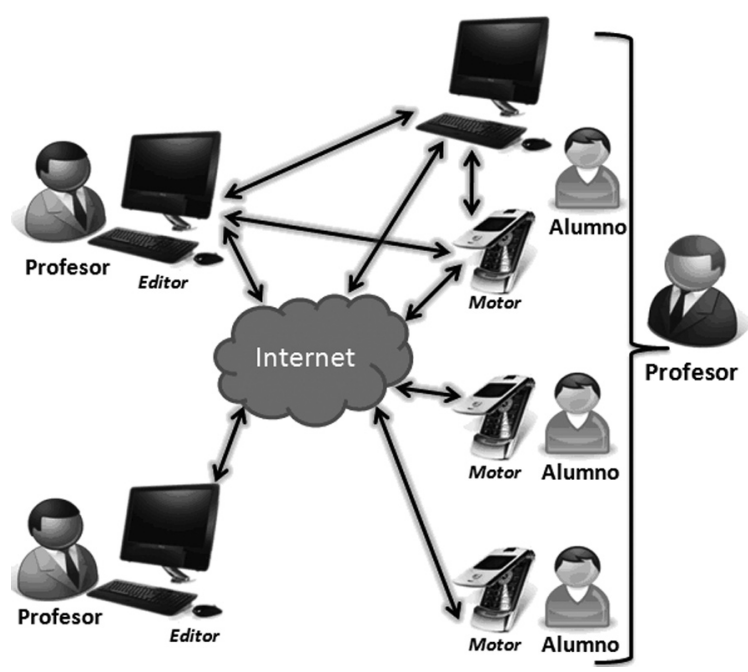

FIGURA 2 - Arquitectura del sistema y su relación con los usuarios

FONTE: Universidad de Chile

Para la comunicación entre los dispositivos se requiere que los profesores cuenten con un acceso a una conexión a Internet para subir o bien mantener en algún lugar de Internet los proyectos generados por ellos a través de un computador de escritorio o un portátil.

En el caso de los alumnos se requiere que estos accedan a Internet directamente a través de sus teléfonos móviles o bien como una segunda opción, que descarguen las guías generadas por sus profesores desde Internet a un computador de escritorio $o$ un portátil que esté a disposición de ellos y desde aquí realicen la transferencia de la guía vía cable o 
Bluetooth a sus teléfonos móviles. Esta última opción deja abierta la posibilidad de que el profesor transfiera directamente los archivos desde su computador de escritorio o portátil donde trabaja con el editor.

\subsection{Funcionamiento del Sistema}

El sistema fue pensado para ser usado tanto dentro como fuera de la sala de clases. El diagrama de la figura 3 muestra el proceso que sigue la realización de una sesión de trabajo por parte de profesores y alumnos con el sistema mGuías.

Utilizando el editor, el profesor crea y edita una o varias guías de trabajo para sus alumnos, incorporando los contenidos que estime conveniente.

En el mismo editor el profesor determina en qué momento generar (o exportar) un proyecto de guía de trabajo, obteniendo como resultado una aplicación para teléfonos móviles (o motor) que contiene los datos de la guía diseñada.

A continuación el profesor debe realizar la distribución a sus alumnos, del motor que contiene los datos de la guía de trabajo. Esto se puede lograr de distintas formas. Una opción es que el profesor suba la aplicación móvil en algún servicio web de Internet o de red local, el cual permita la descarga de archivos a través de una URL por parte de los alumnos o bien simplemente enviarlas por correo electrónico a sus alumnos, con lo cual los alumnos descargan la guía de trabajo a su teléfono móvil u opcionalmente a un computador de escritorio o portátil, y desde este último, pueden transferir la aplicación móvil al teléfono.

Otras opciones consisten en conectar los teléfonos móviles de los alumnos al computador de escritorio o portátil del profesor. De esta forma el profesor puede transferir la guía de trabajo directamente a sus alumnos.

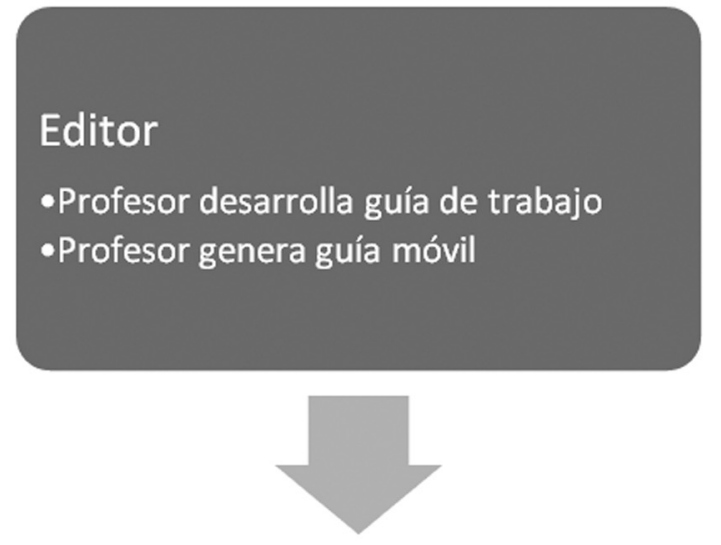

\section{Medio de Distribución}

-Profesor escoge un medio (Editor 1.0)

-Editor mantiene repositorio a través de Internet (Editor 2.0)

-Profesor distribuye guía móvil

-Alumno descarga guía móvil

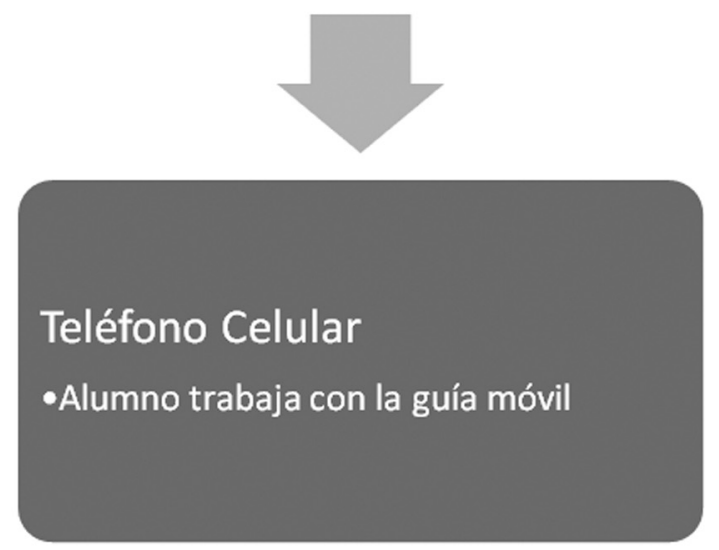

FIGURA 3 - Diagrama del proceso de una sesión de trabajo con el sistema

FONTE: Universidad de Chile

Como se verá más adelante en la descripción del editor 2.0, dicha versión del editor mantiene un repositorio de los proyectos de un profesor en Internet, lo que simplifica el proceso de distribución por parte de los profesores. 
Una vez que el alumno descarga el motor que contiene la guía desarrollada por su profesor, puede proceder a ejecutarla desde su teléfono móvil y comenzar a trabajar con ella en las distintas actividades de aprendizaje que involucra la guía de trabajo.

\subsection{Estructura de las Guías}

Tomando como referencia una guía impresa en papel, se observó que es común que estas guías tengan una sección donde se presentan contenidos y otra sección donde se proponen ejercicios para ser desarrollados por los alumnos. Siguiendo esta mismo estilo de guías, se traspasó esta idea al formato digital, incorporando ciertas restricciones convenientes y justificadas por las restricciones de visualización que tiene el dispositivo donde en definitiva los alumnos trabajaron con las guías, es decir, el teléfono móvil.

En consecuencia para efectos del sistema mGuías, estructuralmente cada guía se compone de un apunte de contenidos y un cuestionario de trabajo. Cada apunte se compone de un determinado número de páginas definidas por el profesor. Cada una de estas páginas contiene un título, una imagen y un párrafo de texto. A su vez, cada cuestionario se compone de un determinado número de preguntas de alternativas definidas por el profesor, donde cada pregunta a su vez, está compuesta de un enunciado, una imagen opcional y cinco alternativas (ver figura 4).

Esta restricción impuesta para la distribución de los elementos de una guía, está pensada para ajustar y aprovechar en forma estándar la visualización de las guías de trabajo en teléfonos móviles con pantallas de dimensiones que van desde $128 \times 128$ a $240 \times 320$ pixeles, lo que ayuda a que los elementos de una página de contenidos o de una pregunta del cuestionario puedan ser claramente identificables y visibles.

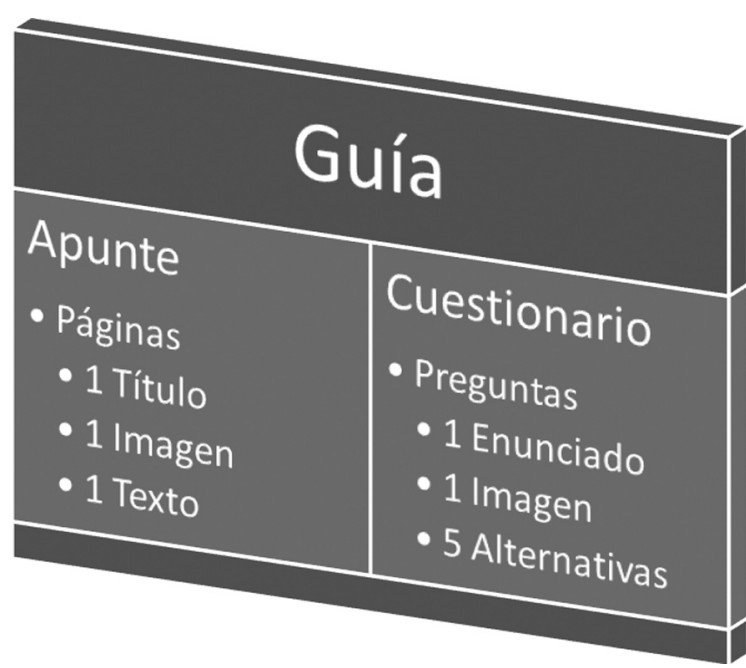

FIGURA 4 - Estructura de una guía con sus respectivos elementos FONTE: Universidad de Chile

\subsection{Editor mGuías}

Como se señaló anteriormente, el editor de mGuías es un módulo del sistema que corresponde a una aplicación para PC, donde el profesor puede editar sus proyectos. Para este módulo se desarrollaron 2 prototipos, el Editor 1.0 que se caracteriza por ser una aplicación de escritorio y el Editor 2.0 que consiste en una versión web a la cual se le incorporaron características mejoradas en comparación a la versión 1.0. A continuación se describe en detalle en qué consisten estos prototipos.

\subsubsection{Editor 1.0}

Esta versión del editor fue una aplicación para PC implementada con el lenguaje C\# en Visual Studio 2008 (ver Figura 5), donde el profesor puede crear apuntes de contenido y cuestionarios de preguntas de alternativas.

En el caso de los apuntes de contenido (ver Figura 6), el editor provee 2 botones, uno que permite añadir y otro que permite borrar páginas de contenido. En el formulario de cada pá- 
gina de contenido el editor dispone de 2 campos de texto, uno para añadir el título y otro para añadir un párrafo de texto. Además, hay un área que muestra la imagen que se puede añadir a la página; bajo esta área hay 2 botones, uno para añadir una imagen disponible en el computador y otro para quitar la imagen vinculada a la página.

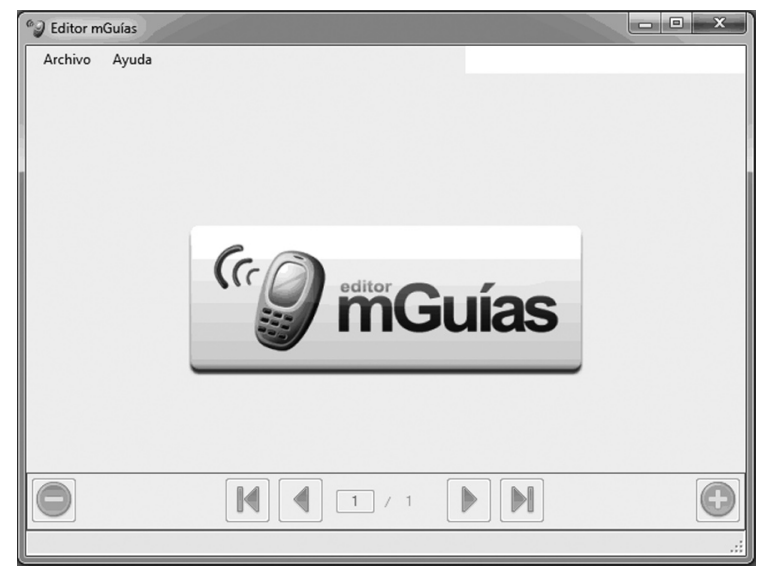

FIGURA 5 - Editor 1.0 Pantalla de inicio FONTE: Universidad de Chile

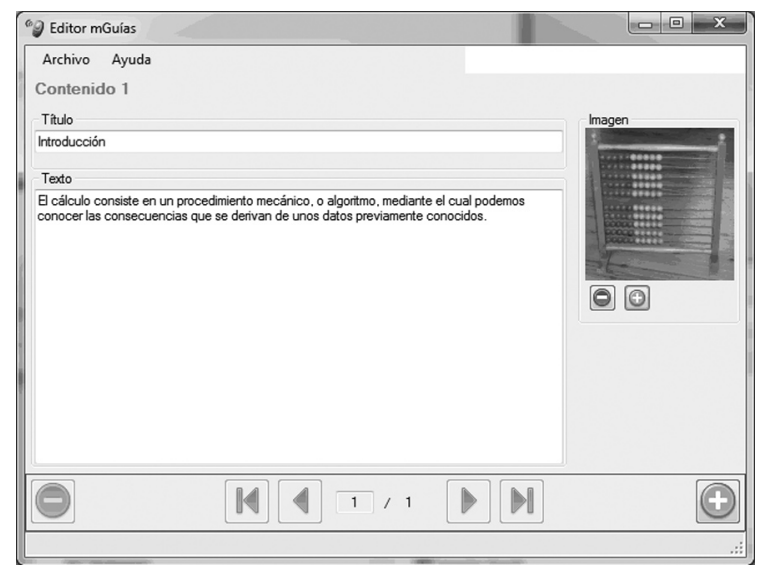

FIGURA 6 - Editor 1.0 Formulario de edición de una página de contenidos

FONTE: Universidad de Chile

En el caso de los cuestionarios (ver Figura 7), el editor provee 2 botones, uno que permi- te añadir preguntas y otro que permite borrar preguntas del cuestionario. En el formulario de cada pregunta, el editor dispone de 6 campos de texto, uno para añadir el texto de la pregunta y otros 5 para añadir alternativas de respuesta, disponiendo de un radio button para marcar la alternativa correcta. Además, hay un área que muestra la imagen que se puede añadir a la pregunta, bajo esta área hay 2 botones, uno para añadir una imagen disponible en el computador y otro para quitar la imagen vinculada a la pregunta.

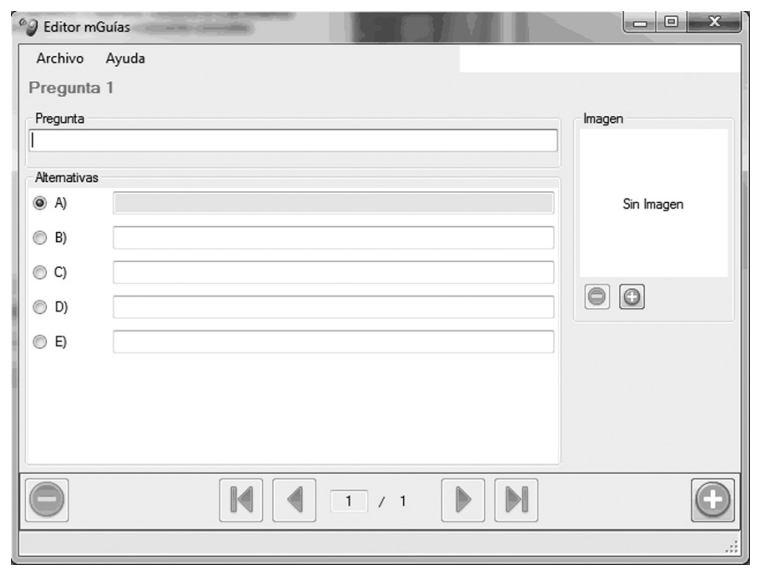

FIGURA 7 - Editor 1.0 Formulario de edición de una pregunta de un cuestionario FONTE: Universidad de Chile

El profesor puede guardar en su PC, el apunte o el cuestionario que se encuentra desarrollando cada vez que estime conveniente, para ello debe establecer un nombre de archivo existente o bien establecer un nuevo nombre de archivo.

Con los apuntes y cuestionarios que fueron guardados en el computador y que previamente fueron generados con el editor, el profesor puede generar una guía de trabajo con la opción Exportar que está disponible en el menú. Esta opción permite al profesor buscar un apunte y un cuestionario en el computador, los cuales se combinan con el motor 
que describiremos más adelante, generando como resultado una aplicación para teléfonos celulares que se almacena en el computador. Esta aplicación para teléfonos celulares debe ser distribuida a través de algún medio por el profesor a sus alumnos, y así, estos últimos estarían en condiciones de poder realizar la instalación en sus dispositivos.

\subsubsection{Editor 2.0}

En la segunda versión del editor se desarrolló una aplicación web implementada en Adobe Flex y PHP, que mantuvo las características que resultaron bien evaluadas en el Editor 1.0, pero mejorando aspectos que resultaron deficientes en la primera versión, además de incorporar características nuevas que fueron necesarias dado el contexto web del sistema en esta nueva versión del editor.

Se incorporó la autentificación de los usuarios en el sistema (ver Figura 8), para proceder con el acceso y la vinculación de las cuentas con los apuntes y cuestionarios creados por cada usuario, mejorando la organización y facilitando la presentación de los datos.

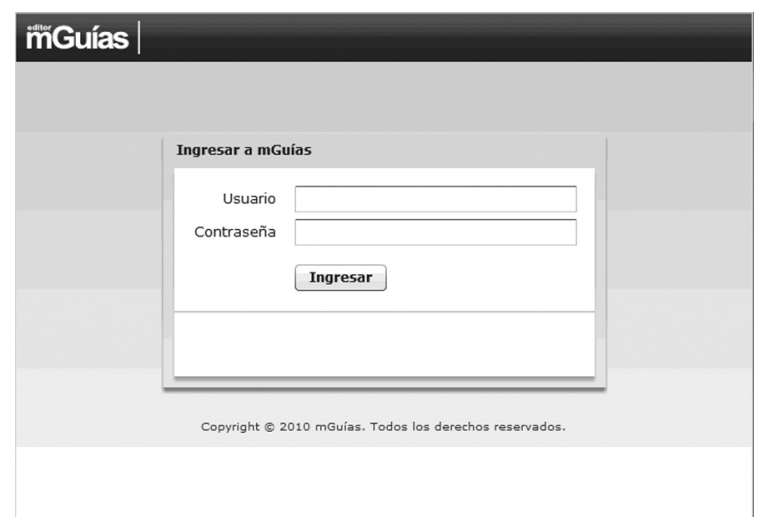

FIGURA 8 - Editor 2.0 Formulario de ingreso al sistema FONTE: Universidad de Chile
También se añadió un administrador de apuntes y cuestionarios (ver Figura 9), que corresponde a la pantalla principal de la aplicación, donde se muestra una lista de apuntes y cuestionarios creados por el profesor y que están disponibles para ser exportados en una guía de trabajo ejecutable en los teléfonos celulares. En este administrador el profesor puede añadir, editar y eliminar apuntes y cuestionarios.

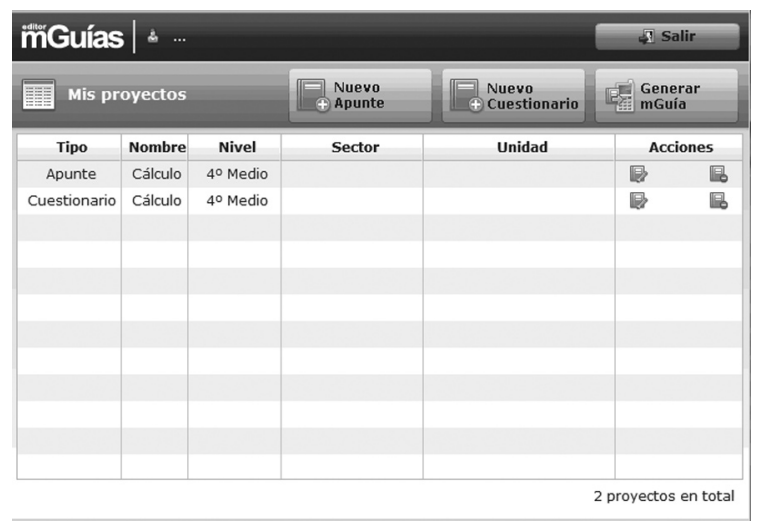

FIGURA 9 - Editor 2.0 Administrador de apuntes y cuestionarios

FONTE: Universidad de Chile

Al momento de añadir o editar un apunte o un cuestionario desde el administrador, se produce un cambio de contexto al formulario respectivo, los cuales mantienen las mismas funcionalidades de los formularios de apuntes y cuestionarios diseñados e implementados en el editor 1.0 (ver Figura 10 y Figura 11). La única diferencia en estos nuevos formularios es que los textos y las fotos se suben a través de internet desde el computador al servidor donde está alojado el sistema mGuías.

La opción de exportar (o generar) un apunte y un cuestionario a una aplicación para teléfonos celulares ahora está disponible a través de un botón en el panel superior del administrador de proyectos. Esta opción al igual que en la primera versión del editor permite 


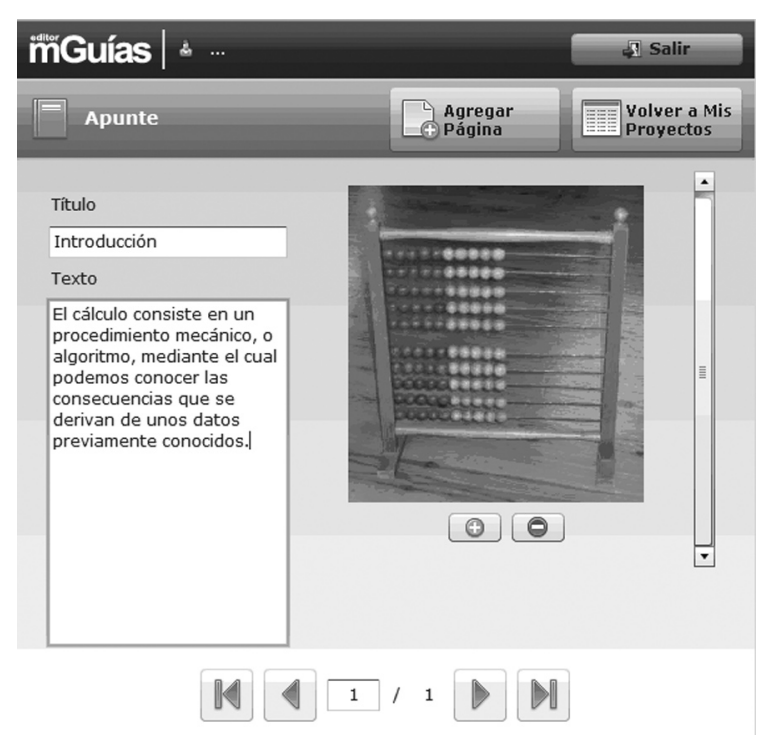

FIGURA 10 - Editor 2.0 Formulario de página de un apunte FONTE: Universidad de Chile

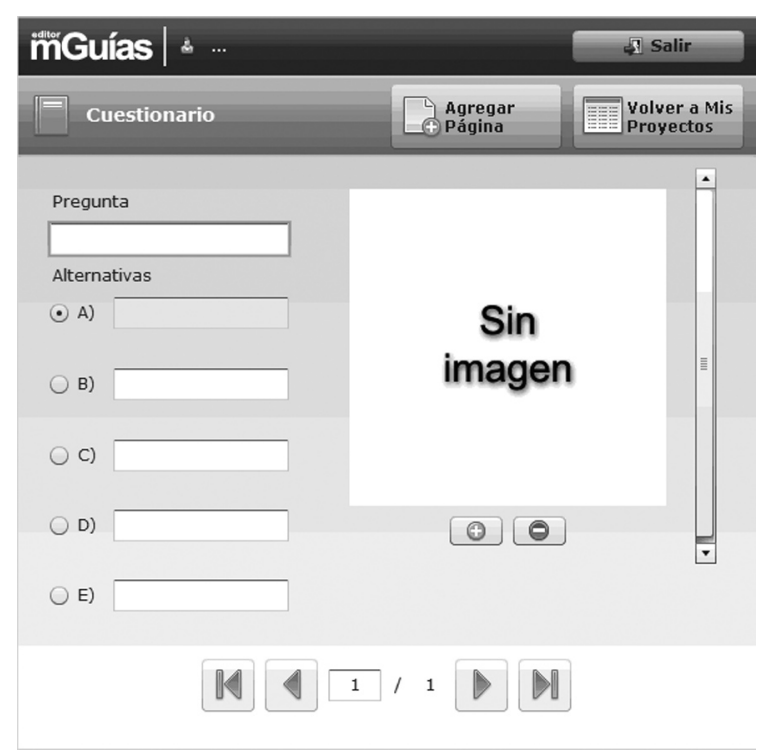

FIGURA 11 - Editor 2.0 Formulario de pregunta de un cuestionario

FONTE: Universidad de Chile buscar un apunte y un cuestionario, pero en esta ocasión se generan 2 listas agrupadas en 2 comboBox, vinculando en cada una de ellas los apuntes y cuestionarios respectivos del usuario; con esto el profesor puede elegir más rápidamente los que le interesan, facilitando considerablemente este proceso. En esta misma línea, otra característica importante que fue incorporada consiste en que la aplicación para teléfonos celulares exportada por el profesor ahora queda disponible a través de la web en un espacio de proyectos exportados vinculados al profesor que lo creó, facilitando considerablemente la distribución de la aplicación a los alumnos.

\subsection{Motor}

El motor de la aplicación para teléfonos móviles fue implementado con el lenguaje J2ME en NetBeans. El motor está construido de tal forma de poder combinarse fácilmente con los datos estructurados de apuntes y cuestionarios exportados desde el editor, permitiendo a los alumnos trabajar con las guías de trabajo creadas por los profesores, es decir, trabajar con el apunte y el cuestionario de la guía de trabajo (ver Figura 12 y Figura 13).

Una característica importante del motor es que ajusta los textos al tamaño de la pantalla del dispositivo, es decir, la misma aplicación se usa para teléfonos con distintas resoluciones de pantalla (las resoluciones de pantalla más comunes son de $128 \times 128,128 \times 160,176 \times 220$ y $240 \times 320$ pixels).

Para la interacción del usuario, el motor utiliza los botones Arriba, Abajo, Izquierda, Derecha y Central del joystick del teléfono (ver Figura 14) y opcionalmente las teclas 8 , 2, 4, 6 (como direccionales) y 5 (como botón central) para reemplazar el joystick en situaciones especiales donde el teléfono celular no reconoce los botones. 


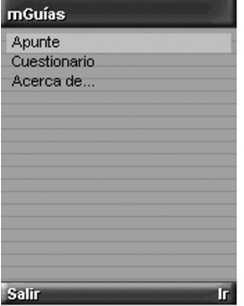

(I)

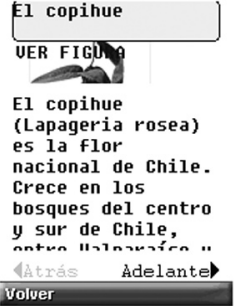

(II)

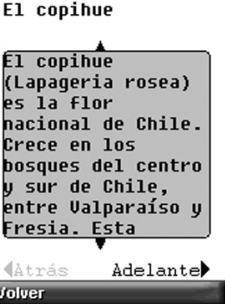

(III)
FIGURA 12 - Motor: (I) Pantalla inicial. (II) Página de contenidos. (III) Scroll de texto sobre el documento FONTE: Universidad de Chile

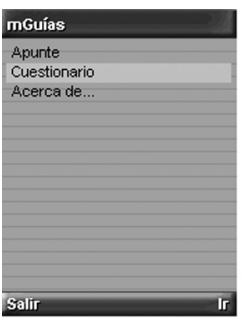

(1)

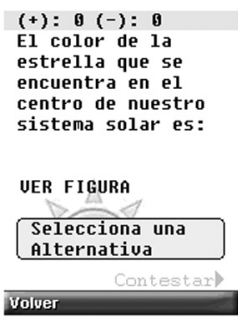

(II)

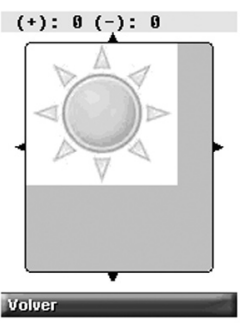

(III)
FIGURA 13 - Motor: (I) Pantalla inicial. (II) Pregunta del cuestionario. (III) Imagen desplegada a pantalla completa FONTE: Universidad de Chile

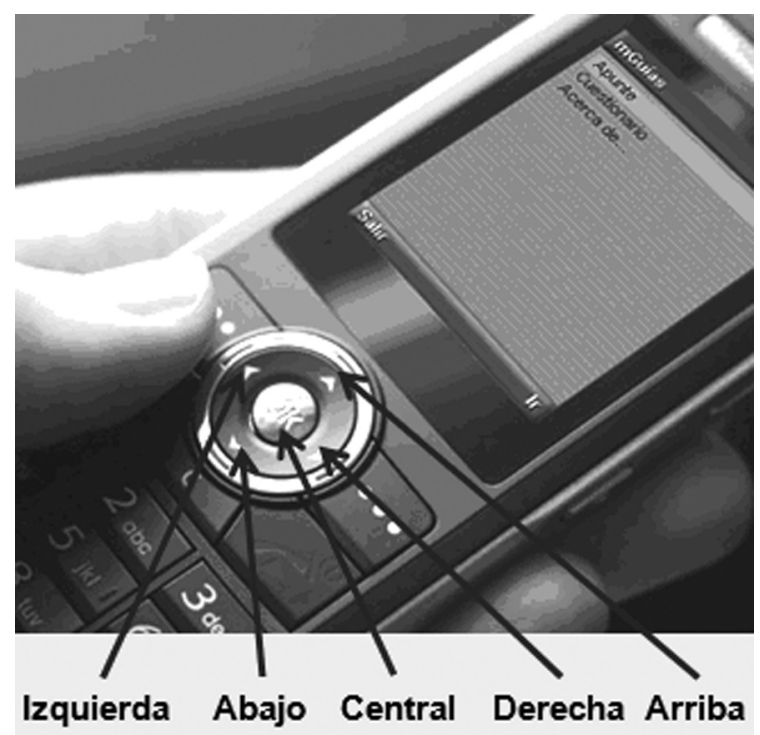

FIGURA 14 - Joystick del teléfono móvil FONTE: Universidad de Chile
En una página del apunte o bien en una pregunta del cuestionario los botones direccionales Arriba y Abajo del joystick sirven para cambiar de foco entre los elementos seleccionables de la interfaz. A su vez, el botón Central del joystick sirve para confirmar la selección de un elemento y realizar la acción asociada.

En una página del apunte el alumno puede cambiar de foco por el título, la imagen, el cuerpo del documento, el vínculo Adelante y el vínculo Atrás. Al presionar el botón Central con el foco sobre en el titulo, se despliega un scroll de texto en caso que el área no sea suficiente para mostrar todo el texto. Al presionar el botón Central con el foco sobre la imagen, se despliega en pantalla completa, permitiendo moverse por la imagen con las teclas Arriba, Abajo, Izquierda y Derecha. Al presionar el botón Central con el foco sobre el cuerpo del documento, se despliega un scroll de texto en caso que el área no sea suficiente para mostrar todo el texto. En el caso de entrar al título, a la imagen o bien al cuerpo del documento, se puede volver a la pantalla normal de la página presionando el botón Central. Finalmente, los vínculos Adelante y Atrás sirven para navegar libremente a través del apunte, y donde al presionar el botón central cuando el foco está sobre ellos se produce el cambio de página hacia adelante o hacia atrás según corresponda.

En una pregunta del cuestionario el alumno puede cambiar de foco entre el enunciado, la imagen, el campo de alternativas y el vínculo Contestar. Al presionar el botón Central con el foco sobre el enunciado, se despliega un scroll de texto en caso que el área no sea suficiente para mostrar todo el texto. Al presionar el botón Central con el foco sobre la imagen, esta se despliega en pantalla completa, permitiendo moverse por la imagen con las teclas Arriba, Abajo, Izquierda y Derecha. Al presionar 
el botón Central con el foco sobre el campo de alternativas, queda disponible la opción de recorrer las alternativas con los botones Izquierda y Derecha del joystick, además está disponible un scroll de texto con 2 líneas visibles en caso que el área no sea suficiente para mostrar todo el texto de la alternativa. Para elegir una alternativa sólo basta con presionar nuevamente el botón Central del joystick. En el caso de entrar al enunciado o a la imagen, se puede volver a la pantalla normal de la pregunta presionando el botón Central. Finalmente, el vínculo Continuar sirve para confirmar la respuesta con la alternativa seleccionada y pasar a la siguiente pregunta.

\section{Metodología}

Los módulos del sistema descritos anteriormente fueron sometidos a evaluaciones de usabilidad, Nielsen (1993), con usuarios finales, profesores en el caso del editor y alumnos en el caso del motor (ver Figura 15 y Figura 16). A continuación se profundiza en la metodología empleada para la evaluación de estos módulos.

\subsection{Muestra}

Para la evaluación se contó con 2 muestras independientes de profesores, las que denominaremos muestra no 1 de profesores y muestra $n^{\circ} 2$ de profesores, y además se contó con 2 muestras independientes de alumnos, las que denominaremos muestra no1 de alumnos y muestra no2 de alumnos. Todos ellos pertenecen a ciudades del centro y sur de Chile afectadas por el terremoto.

Tanto los profesores como los alumnos fueron dispuestos por los colegios a los cuales pertenecían, de acuerdo a su disponibilidad y las facilidades de cada institución, factores que determinaron las cantidades y características
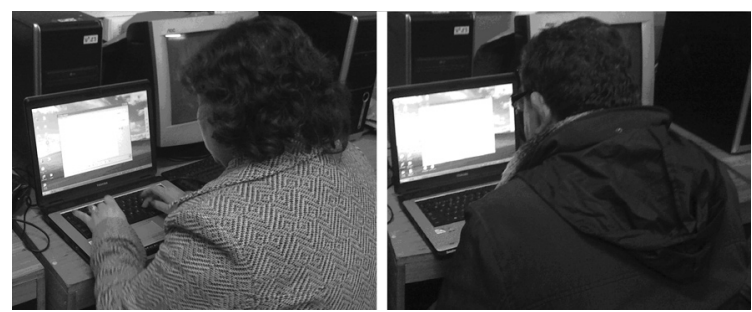

FIGURA 15 - Profesores que participaron en el estudio de usabilidad de mGuías FONTE: Universidad de Chile

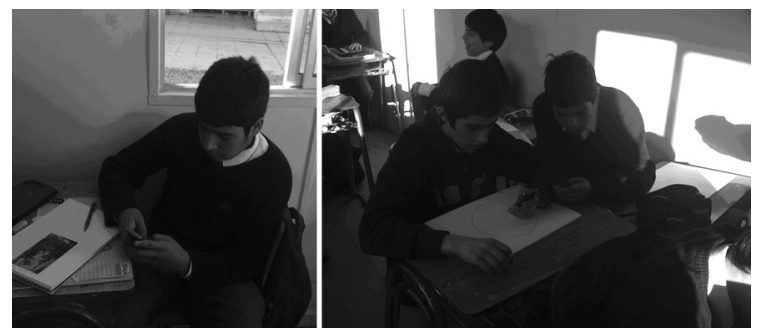

FIGURA 16 - Alumnos que participaron en el estudio de usabilidad de mGuías FONTE: Universidad de Chile

de los usuarios de nuestra muestra en forma independiente. A través de los instrumentos utilizados en el procedimiento, que serán descritos más adelante, se obtuvo la edad, género, conocimiento computacional y conocimiento en uso de teléfonos móviles de los usuarios.

La muestra n ${ }^{0} 1$ de profesores estuvo compuesta por 17 usuarios, 8 de género femenino y 9 de género masculino, pertenecientes al Liceo Abate Molina y al Liceo Marta Donoso Espejo, ubicados en la ciudad de Talca, y al Colegio Talcahuano, al Liceo Comercial de Talcahuano y al Colegio Inmaculada Concepción ubicados en la ciudad de Talcahuano. El conocimiento computacional declarado por ellos arrojó los siguientes valores: 3 en nivel básico, 10 en nivel medio y 4 en nivel avanzado. El rango de edades de los profesores fue desde los 22 a los 64 años, teniendo las siguientes cantidades de profesores por edad: 1 de 22 años, 1 de 25 años, 1 de 28 años, 1 de 35 años, 1 de 40 años, 1 de 44 años, 1 de 46 años, 1 
de 47 años, 1 de 48 años, 1 de 53 años, 1 de 54 años, 1 de 57 años, 1 de 59 años, 2 de 60 años, 1 de 62 años y 1 de 64 años.

La muestra n02 de profesores estuvo compuesta por 11 usuarios, 6 de género femenino y 5 de género masculino, pertenecientes al Liceo Diego Portales ubicado en la ciudad de Talca. El conocimiento computacional declarado por ellos arrojó los siguientes valores: 1 en nivel básico, 8 en nivel medio y 2 en nivel avanzado. El rango de edades de los profesores fue desde los 24 a los 60 años, teniendo las siguientes cantidades de profesores por edad: 1 de 24 años, 1 de 30 años, 2 de 38 años, 1 de 50 años, 1 de 53 años, 1 de 56 años, 3 de 58 años y 1 de 60 años.

La muestra n०1 de alumnos estuvo compuesta por 104 usuarios, 52 de género femenino y 52 de género masculino, pertenecientes al Liceo Abate Molina y al Liceo Marta Donoso Espejo ubicados en la ciudad de Talca, y al Colegio Talcahuano, al Liceo Comercial de Talcahuano y al Colegio Inmaculada Concepción ubicados en la ciudad de Talcahuano. El conocimiento en uso de teléfonos celulares declarado por ellos arrojó los siguientes valores: 4 en nivel básico, 62 en nivel medio y 38 en nivel avanzado. El rango de edades de los alumnos va desde los 13 a los 18 años, teniendo las siguientes cantidades de alumnos por edad: 1 de 13 años, 21 de 14 años, 1 de 15 años, 21 de 16 años, 54 de 17 años y 5 de 18 años.

La muestra $\mathrm{n}^{0} 2$ de alumnos estuvo compuesta por 5 usuarios, 3 de género femenino y 2 de género masculino, pertenecientes al Liceo Polivalente Guillermo Labarca Hube A78 ubicado en la ciudad de Santiago; todos con 17 años de edad y con un nivel medio de conocimiento en uso de teléfonos celulares.

\subsection{Instrumentos}

Se utilizaron dos adaptaciones del cuestio- nario de usabilidad de usuario final, Sánchez (2003), una para el editor y otra para el motor (ver Figura 17 y Figura 18). El cuestionario original constó de afirmaciones que el usuario debe evaluar de 1 a 10 , donde 1 es poco y 10 es mucho, además de campos donde el usuario registra su edad, género y nivel de conocimiento computacional, y una sección con las siguientes preguntas abiertas: ¿Qué te gustó del software?, ¿Qué no te gustó del software? ¿Qué agregarías al software?, ¿Para qué crees que te puede servir el software?, ¿Qué otros usos le darías al software?, y Observaciones. Las adaptaciones consistieron en cambiar la palabra software por editor en las afirmaciones del cuestionario de usabilidad para evaluar el editor, y en aumentar la cantidad de preguntas y reemplazar el campo nivel de conocimiento computacional por nivel de conocimiento en uso de teléfonos celulares en el caso del cuestionario de usabilidad para evaluar el motor. El cuestionario utilizado para evaluar la usabilidad del editor constó de 10 afirmaciones que fueron evaluadas por las muestras $\mathrm{n}^{0} 1 \mathrm{y}$ n02 de profesores. A su vez, el cuestionario para evaluar la usabilidad del motor constó de 24 afirmaciones que fueron evaluadas por la muestra $\mathrm{n}^{0} 1$ de alumnos (en los resultados se pueden ver las afirmaciones de ambos cuestionarios de usabilidad). Con el uso de estos cuestionarios de usabilidad se buscó evaluar la calidad del editor y del motor a través de la satisfacción de los usuarios respectivos, en temas de control, uso, aceptación y diseño.

Se utilizó una pauta de observación, con secciones para medir la eficiencia, el error y el nivel de aprendizaje del uso del motor de la muestra $\mathrm{n}^{0} 2$ de alumnos. Con el apoyo de esta pauta, un facilitador registró el tiempo que toman los alumnos para realizar las tareas. Además, esta pauta contempló una sección donde el evaluador registró los errores más comunes del usuario, tales como no expandir textos ex- 


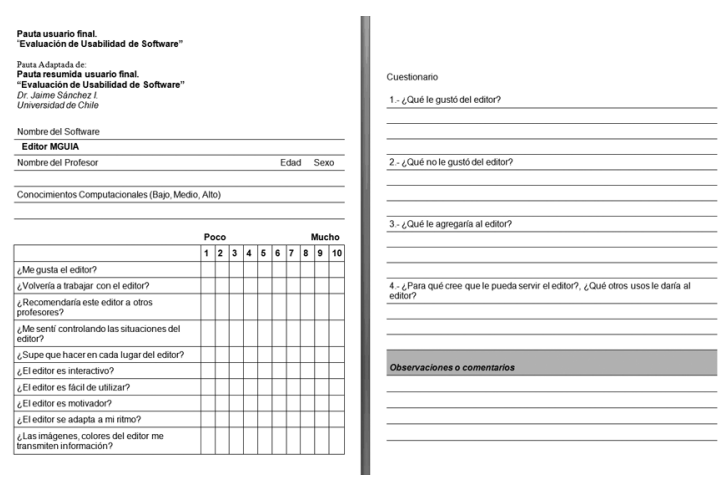

FIGURA 17 - Cuestionario de usabilidad adaptado para el editor

FONTE: Universidad de Chile
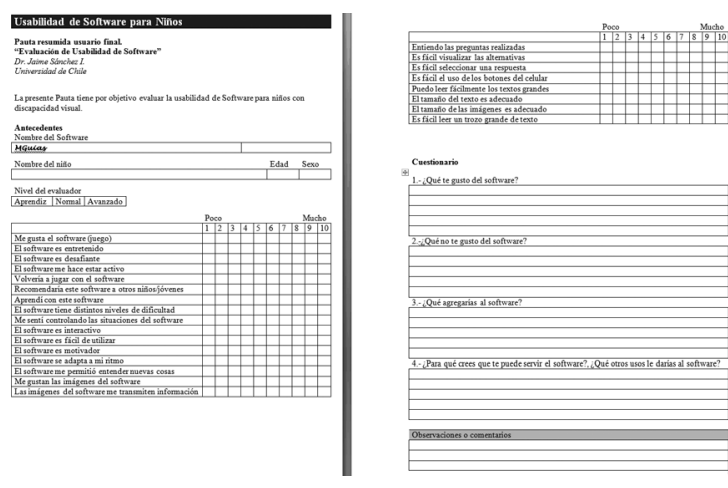

FIGURA 18 - Cuestionario de usabilidad adaptado para el motor

FONTE: Universidad de Chile

tensos y no expandir la imagen en el apunte y en el cuestionario perteneciente a la guía de trabajo en el teléfono celular. Para registrar el aprendizaje de la interfaz hay indicaciones en la pauta de observación que solicitan al usuario la ejecución de tareas específicas a ser realizadas luego de efectuar las tareas globales. Algunas de estas tareas son expandir texto e imágenes específicas y cambiar de páginas en el apunte, encontrar, seleccionar y contestar con una alternativa específica en una pregunta del cuestionario. Además, esta pauta de observación tenía campos para registrar la edad, género y nivel de conocimiento en uso de teléfonos celulares de los usuarios antes de iniciar la actividad.

\subsection{Tareas}

Para el uso del editor por parte de los profesores se establecieron tres tareas: Tarea 1. Crear un apunte, Tarea 2, Crear un cuestionario y Tarea 3. Exportar un proyecto con un apunte y un cuestionario creado por el profesor. Para las dos primeras tareas se entregó material digital con textos, preguntas e imágenes. Para el uso del motor por parte de los alumnos se establecieron dos tareas: Tarea 1. Leer un apunte y Tarea 2 . Contestar un cuestionario.

\subsection{Procedimiento}

Se instaló el editor 1.0 en un computador portátil al cual se incorporaron un ratón y un teclado externo. Además, se dispuso en el sistema de archivos del computador portátil el material digital de apoyo para la construcción de apuntes y cuestionarios. Se trabajó individualmente con cada usuario de la muestra n०1 de profesores, a los cuales se les pidió que realizaran las 3 tareas correspondientes al editor. Una vez completadas las tareas, a cada usuario se le entregó una copia impresa del cuestionario de usabilidad de usuario final adaptado para el editor, para que cada profesor lo respondiera.

En una segunda instancia se instaló en 3 teléfonos celulares con J2ME, una aplicación generada con el editor con un apunte de 3 páginas y un cuestionario de 3 preguntas, con contenidos de ciencias, que permitieron poner a prueba las características del motor. Se trabajó en grupos de 3 usuarios correspondientes a la muestra $n^{0} 1$ de alumnos, a los cuales se les pidió que realizaran individualmente las 2 tareas correspondientes al motor. Una vez 
completadas las tareas, a cada usuario se le entregó una copia impresa del cuestionario de usabilidad de usuario final adaptado para el motor, para que cada alumno lo respondiera.

En una tercera instancia se instaló un entorno de servidor de prueba en un computador portátil para permitir que el editor 2.0 se pudiera ejecutar simulando la conexión a través de internet vía localhost. Además, se dispuso en el sistema de archivos del computador portátil el material digital de apoyo para la construcción de apuntes y cuestionarios. Individualmente se trabajó con cada usuario de la muestra $\mathrm{n}^{\circ} 2$ de profesores, a los cuales se les pidió que realizaran las 3 tareas correspondientes al editor. Una vez completadas las tareas, a cada usuario se le entregó una copia impresa del cuestionario de usabilidad de usuario final adaptado para el editor, para que cada profesor lo respondiera.

Finalmente, en la última instancia se instaló en un teléfono celular con J2ME, una aplicación móvil generada con el editor utilizando un apunte de 5 páginas y un cuestionario de 5 preguntas, con contenidos de matemáticas, lo que permitió medir la eficiencia, los errores y el aprendizaje del uso del motor. Se trabajó individualmente con cada usuario de la muestra n०2 de alumnos, a los cuales se les pidió que realizaran las dos tareas correspondientes al motor, las que fueron medidas por un evaluador, el cual completó las secciones de eficiencia y error en una pauta de observación. A continuación se procedió con la sección de aprendizaje de la pauta de observación, una a una se solicitó las tareas específicas de la pauta y se registró su logro.

\section{Resultados}

En la evaluación del editor 1.0 y el editor 2.0 se obtuvo como resultado que las medias de cada afirmación del cuestionario de usabilidad de usuario final mejoraron en el editor 2.0 (ver Tabla 1). Para saber si esta mejora fue estadísticamente significativa se aplicó una prueba T-Student para muestras independientes, la cual arrojó que en cada afirmación el incremento no fue estadísticamente significativo, es decir, las medias son similares. Hay que destacar que los resultados por cada afirmación dan cuenta del alto nivel de aceptación del editor por parte de los usuarios. A continuación se muestra el detalle de los resultados por afirmación: me gusta el editor (media editor $1.0=8,24$ (de un máximo de 10); media editor $2.0=8,91)$, volvería a trabajar nuevamente con el editor (media editor $1.0=8,76$; media editor $2.0=9,09$ ), recomendaría el editor a otros profesores (media editor $1.0=8,76$; media editor $2.0=8,82$ ), me sentí controlando el editor (media editor 1.0 =7,63; media editor $2.0=7,82$ ), supe que hacer en cada sección del editor (media editor $1.0=6,82$; media editor $2.0=8,36$ ), el editor es interactivo (media editor $1.0=8,47$; media editor $2.0=8,82)$, el editor es fácil de usar (media editor 1.0=8,41; media editor $2.0=9,18$ ), el editor es motivador (media editor $1.0=8,65$; media editor $2.0=9,00$ ), el editor se ajusta a mi ritmo (media editor $1.0=7,88$; media editor $2.0=8,36$ ) y las imágenes, colores and brillos del editor me entregaron información (media editor 1.0 $=8,71$; media editor $2.0=8,82$ ).

A través de las preguntas abiertas se identificaron algunos aspectos deficientes en el Editor 1.0, y que fueron mejorados en el Editor 2.0. Se mejoró considerablemente la deficiencia detectada en la organización y presentación de los datos por parte de los usuarios, se incorporó un administrador de apuntes y cuestionarios, acompañado por la autentificación de los usuarios. También se facilitó la forma en que los usuarios realizan la exportación de proyectos. Finalmente, se 
TABLA 1 - Media obtenida en las afirmaciones para el Editor 1.0 y el Editor 2.0

\begin{tabular}{|l|c|c|}
\hline \multicolumn{1}{|c|}{ Afirmación } & $\begin{array}{c}\text { Media } \\
\text { Editor 1.0 }\end{array}$ & $\begin{array}{c}\text { Media Editor } \\
\mathbf{2 . 0}\end{array}$ \\
\hline Me gusta el editor & 8,24 & 8,91 \\
\hline $\begin{array}{l}\text { Volvería a trabajar } \\
\text { nuevamente con el } \\
\text { editor }\end{array}$ & 8,76 & 9,09 \\
\hline $\begin{array}{l}\text { Recomendaría } \\
\text { el editor a otros } \\
\text { profesores }\end{array}$ & 8,76 & 8,82 \\
\hline $\begin{array}{l}\text { Me sentí controlando } \\
\text { el editor }\end{array}$ & 7,63 & 7,82 \\
\hline $\begin{array}{l}\text { Supe que hacer en } \\
\text { cada sección del } \\
\text { editor }\end{array}$ & 8,82 & 8,36 \\
\hline $\begin{array}{l}\text { El editor es } \\
\text { interactivo }\end{array}$ & 8,47 & 8,82 \\
\hline $\begin{array}{l}\text { El editor es fácil de } \\
\text { usar }\end{array}$ & 8,81 & 9,18 \\
\hline $\begin{array}{l}\text { El editor es } \\
\text { motivador }\end{array}$ & 8,65 & 9 \\
\hline $\begin{array}{l}\text { El editor se ajusta a } \\
\text { mi ritmo }\end{array}$ & & \\
\hline $\begin{array}{l}\text { Las imágenes, } \\
\text { colores and } \\
\text { brillos del editor } \\
\text { me entregaron } \\
\text { información }\end{array}$ & \\
\hline
\end{tabular}

FONTE: Universidad de Chile

mejoró la interfaz en general, incorporando una nueva iconografía y una mejor distribución de los botones.

En la evaluación del motor se obtuvieron los siguientes resultados por cada una de las afirmaciones del cuestionario de usabilidad de usuario final (ver Tabla 2): me gusta el software (media $=7,17$ (de un máximo de 10)), el software es entretenido (media $=6,68$ ), el software es desafiante (media $=7,50)$, el software me hace estar activo (media=6,95), trabajaría con el software nuevamente (media=7,85), recomendaría este software a otros estudiantes (media=8,46), aprendí usando el software (media=6,39), el software tiene
TABLA 2 - Media obtenida en las afirmaciones para el Motor

\begin{tabular}{|c|c|}
\hline Afirmación & Media Motor \\
\hline Me gusta el software & 7,17 \\
\hline El software es entretenido & 6,68 \\
\hline El software es desafiante & 7,5 \\
\hline El software me hace estar activo & 6,95 \\
\hline $\begin{array}{l}\text { Trabajaría con el software } \\
\text { nuevamente }\end{array}$ & 7,85 \\
\hline $\begin{array}{l}\text { Recomendaría este software a } \\
\text { otros estudiantes }\end{array}$ & 8,46 \\
\hline Aprendí usando el software & 6,39 \\
\hline $\begin{array}{l}\text { El software tiene distintos niveles } \\
\text { de dificultad }\end{array}$ & 7,19 \\
\hline $\begin{array}{l}\text { Me sentí controlando las } \\
\text { situaciones en el software }\end{array}$ & 6,8 \\
\hline El software es interactivo & 7,46 \\
\hline El software es fácil de usar & 8,36 \\
\hline El software es motivador & 7,4 \\
\hline El software se adapta a mi ritmo & 7,28 \\
\hline $\begin{array}{l}\text { El software me permitió entender } \\
\text { cosas nuevas }\end{array}$ & 6,36 \\
\hline $\begin{array}{l}\text { Me gustan las imágenes del } \\
\text { software }\end{array}$ & 5,07 \\
\hline $\begin{array}{l}\text { Las imágenes del software me } \\
\text { entregan información }\end{array}$ & 5,98 \\
\hline Entiendo las preguntas realizadas & 7,25 \\
\hline Es fácil visualizar las alternativas & 7,97 \\
\hline Es fácil seleccionar una respuesta & 7,86 \\
\hline $\begin{array}{l}\text { Es fácil el uso de los botones del } \\
\text { celular }\end{array}$ & 8,62 \\
\hline $\begin{array}{l}\text { Puedo leer fácilmente los textos } \\
\text { grandes }\end{array}$ & 8,17 \\
\hline El tamaño del texto es adecuado & 7,22 \\
\hline $\begin{array}{l}\text { El tamaño de las imágenes es } \\
\text { adecuado }\end{array}$ & 4,7 \\
\hline $\begin{array}{l}\text { Es fácil leer un trozo grande de } \\
\text { texto }\end{array}$ & 7,4 \\
\hline
\end{tabular}

FONTE: Universidad de Chile

distintos niveles de dificultad (media=7,19), me sentí controlando las situaciones en el software (media $=6,80$ ), el software es interactivo (media $=7,46$ ), el software es fácil de usar (media=8,36), el software es motivador 
(media $=7,40)$, el software se adapta a mi ritmo (media=7,28), el software me permitió entender cosas nuevas (media=6,36), me gustan las imágenes del software (media=5,07), las imágenes del software me entregan información (media $=5,98$ ), entiendo las preguntas realizadas (media $=7,25)$, es fácil visualizar las alternativas (media $=7,97$ ), es fácil seleccionar una respuesta (media=7,86), es fácil el uso de los botones del celular (media=8,62), puedo leer fácilmente los textos grandes (media $=8,17)$, el tamaño del texto es adecuado (media=7,22), el tamaño de las imágenes es adecuado (media $=4,70$ ) y es fácil leer un trozo grande de texto (media=7,40). En general, los resultados obtenidos dan cuenta de una alta aceptación del motor por parte de los alumnos, salvo por algunos aspectos como el manejo y visualización de las imágenes de la aplicación, que dadas las características de los teléfonos celulares, es un resultado difícil de revertir.

Los resultados de la observación del uso del motor evidenciaron que los alumnos realizaron las dos tareas en torno al tiempo esperado de realización de las actividades: la tarea 1 con el apunte (tiempo esperado=5 minutos; media $=4$ minutos 12 segundos) y la tarea 2 con el cuestionario (tiempo esperado $=10 \mathrm{mi}-$ nutos; media=10 minutos 12 segundos). En cuanto a la observación de errores, los resultados evidencian que en general los alumnos redujeron sus errores a medida que avanzaban en las preguntas. Si inicialmente en los apuntes o cuestionarios no expandían los textos ni las imágenes, al llegar al final de estos, ya no cometían este error. La observación del aprendizaje de la interfaz mostró que los alumnos fallaron sólo en las primeras tareas específicas, no así en las últimas. En consecuencia, los usuarios disminuyeron sus errores progresivamente hasta cero al desarrollar las tareas con el motor.

\section{Conclusiones}

El objetivo de este trabajo fue introducir el sistema mGuías y presentar el impacto de las evaluaciones de usabilidad como parte del proceso de desarrollo del sistema.

Las evaluaciones de usabilidad fueron útiles para validar los elementos que fueron diseñados e implementados en cada módulo y también sirvieron para detectar problemas en el diseño que llamaron a rediseñar algunos elementos en la siguiente versión, como fue en el caso del Editor. Como resultado, las evaluaciones de usabilidad apoyaron el desarrollo del sistema mGuías, validando el diseño actual del Motor y llamando a los desarrolladores a mejorar el sistema en la siguiente versión del Editor, a través del feedback aportado por los resultados obtenidos en las evaluaciones de usabilidad, esto siempre alineado con entregar una herramienta simple y fácil de usar para el usuario final de cada módulo del sistema mGuías.

Los resultados del editor muestran que en la versión 2.0 mejoró en cada uno de los indicadores de usabilidad y que si bien dichos incrementos o mejoras no fueron estadísticamente significativos, en los resultados de ambas evaluaciones, tanto el editor $1.0 \mathrm{y}$ el editor 2.0, fueron claramente aceptados por los profesores, evidenciando que el editor es una herramienta usable y comprensible, lo que valida el diseño de sus componentes. El editor permite al profesor fácilmente crear, editar y generar un proyecto de guía de trabajo para sus estudiantes, sin embargo es labor del profesor asegurarse que los contenidos del apunte son presentados en un orden lógico adecuado y que las preguntas del cuestionario estén relacionadas con los contenidos presentados en el apunte.

Los resultados del motor muestran a través de sus indicadores de usabilidad, una 
buena aceptación en general por parte de los alumnos. El punto bajo está en el manejo y visualización de las imágenes, justificado principalmente por el tamaño reducido de la pantalla de los teléfonos celulares. Los aspectos interesantes observados en el uso del motor por los alumnos fueron: que permite a los usuarios realizar tareas dentro de los tiempos esperados, que es muy intuitivo y que cuesta poco aprender usarlo.

El diseño de este sistema fue muy acertado desde el punto de vista de la autonomía y libertad de trabajo para los usuarios, dado el contexto y la situación crítica al cual estaba enfocado, la situación de emergencia generada por el terremoto y la necesidad de proveer de guías de aprendizaje y cuestionarios móviles para su uso con un teléfono celular a los alumnos que no tenían lugar físico para aprender formalmente (liceo) o tenían problemas de acceso a estos centros de aprendizaje. Aspectos que pueden ayudar en iniciativas similares emprendidas por otros investigadores.

Como trabajo futuro se plantea seguir mejorando y ampliando las características del sistema. En este sentido, se plantea evaluar una versión del sistema a través de un servicio web en producción, el cual permitiría probar la calidad del proceso de generación y descarga de guías a través de internet que involucra a profesores y alumnos. Asimismo, se plantea la incorporación de aspectos no considerados en el diseño inicial, como restringir el acceso a las guías publicadas, asociando su acceso a cuentas de usuario para alumnos específicos en el sistema, y el envío de feedback al profesor, con los resultados obtenidos por los alumnos en las guías. También está pendiente la adopción de un modelo de negocios para el sistema, lo que permitiría determinar la forma en que se asumen los costos de descarga de las guías a través de internet. En las evaluaciones de usabilidad se utilizaron teléfonos celulares con J2ME instalado, que no pertenecían a los alumnos, por esta razón no hubo problemas de costos ni requerimientos. También en el marco de los teléfonos celulares, se impuso como restricción de diseño, optar sólo por teléfonos móviles que permiten ingreso de datos a través de su joystick y teclado numérico, dejando fuera a los teléfonos que tienen pantalla táctil como interfaz de entrada de datos para el usuario. En este sentido queda propuesto como trabajo futuro implementar una versión del motor para dispositivos con pantalla táctil, que permita utilizar dispositivos que gozan actualmente de un auge en su adquisición y uso, tales como teléfonos móviles con sistemas Android e iOS (iPhone).

Finalmente, está pensado ampliar los usos de mGuías a otros contextos y aprovechar el potencial educativo de la herramienta, ya que es directamente integrable al desarrollo de cursos en distintas áreas de aprendizaje y en distintos niveles. Esto involucrará la realización de nuevas evaluaciones de usabilidad y de evaluaciones del impacto cognitivo del uso del sistema. Precisamente a través de las evaluaciones cognitivas se podrá saber de qué forma y con qué impacto mGuías ayuda en el proceso de aprendizaje de los alumnos.

\section{Agradecimientos}

Este trabajo contó con la ayuda de Manuel Ibarra alumno de Magíster en Ciencias de la Computación de la Universidad de Chile, en la evaluación de usabilidad.

Este trabajo ha sido financiado en parte por el Fondo Nacional de Ciencia y Tecnología, Fondecyt \# 1090352, el Proyecto CIE-05 Programa de Centros de Educación PBCT-Conicyt y el Proyecto LWM STIC AMSUD. 


\section{Referencias}

BROWN, M. Handhelds in the classroom. In: EDUCATION World. San Diego: EducationWorld Corporate, 2001. Disponible en: <http://www.educationworld.com/a_tech/tech083.shtml, 2001> Acceso en: 5 Mar. 2012.

CHITTARO, L.; ZULIANI, F.; CARCHIETTI, E. Mobile devices in emergency medical services: user evaluation of a PDA-based interface for ambulance run reporting. In: INTERNATIONAL CONFERENCE ON MOBILE INFORMATION TECHNOLOGY FOR EMERGENCY RESPONSE - MobileResponse'07, 1., 2007, Sankt Augustin, Germany. Proceedings. Berlin: Springer-Verlag, 2007. P. 19-28.

CNN. More than 2 million affected by earthquake, Chile's president says. 2010. Disponible en: <http://edition.cnn.com/2010/WORLD/americas/02/27/chile.quake/index.html?iref=allsearch> Acceso en: 5 Mar. 2012.

CSETE, J.; WONG, Y.; VOGEL, D. Mobile devices in and out the classroom. In: CANTONI, L.; MCLOUGHLIN (Ed.). Proceedings of ED-MEDIA 2004 World Conference on Educational Multimedia, Hypermedia \& Telecommunications. [S.I.: s.n.], 2004. P. 4729-4736.

EL SIGLO. América Latina es el segundo mercado de celulares más grande del mundo. 2010. Disponible en: <http://www.elsigloweb.com/nota.php?id=55263> Acceso en: 29 Feb. 2012.

FACER, K. et al. Savannah: mobile gaming and learning? Journal of Computer Assisted Learning, Oxford, no. 20, p. 399-409, 2004.

HADDON, L. Domestication and Mobile Telephony. 2001. Paper presented at the conference 'Machines that Become Us' Rutgers University, New Jersey, US, 18th-19th April 2001. Disponible en: < http://www2.Ise. ac.uk/media@Ise/whosWho/AcademicStaff/LeslieHaddon/Domestication\%20and\%20mobile.pdf> Acceso en: 5 Mar. 2012.

JAMES, J. et al. Mobile educational games. In: LASSNER, D.; MCNAUGHT, C. (Ed.). Proceedings of ED-MEDIA 2003 World Conference on Educational Multimedia, Hypermedia \& Telecommunications. [S.I.: s.n.], 2003. P. 801-802.

KANGAS, E.; KINNUNEN, T. Applying user/centered design to mobile application development. Communications of the ACM, New York, n. 48, p. 55-59, july 2005.

KENTERIS, M.; GAVALAS, D.; ECONOMOU, D. An innovative mobile electronic tourist guide application. Personal Ubiquitous Comput, n. 13, p. 103-118, feb. 2009.

MONARES, A. et al. Mobile computing in urban emergency situations: Improving the support to firefighters in the field. Expert Systems with Applications, New York, n. 38, p. 1255-1267, feb. 2011.

NIELSEN, J. Usability engineering. New York: Academic Press Professional, 1993. 
OMAR, A.; LIU, L. C.; KOONG, K. S. From disaster recovery to Mobile Learning: a case study. International Journal of Mobile Learning and Organization, Geneva, v. 2, no. 1, p. 4-17, june 2008.

POWNELL, D.; BAILEY, G. Getting a handle on handhelds. American School Board Journal, Volume 188, no. 6, p. 18-21, 2001.

SÁNCHEZ, J. End-user and facilitator questionnaire for Software Usability: Usability evaluation test. Santiago, Chile: University of Chile, 2003.

SÁNCHEZ, J.; ESPINOZA, M. Video Game Design for Mobile Phones. In: FORBIG, P.; PATERNÓ, F.; MARKPEJTERSEN, A. (Ed.). IFIP Advances in Information and Communication Technology. Berlin: Springer, 2010. V. 332 , p. $199-210$.

SÁNCHEZ, J.; MENDOZA, C.; SALINAS, A. Mobile serious games for collaborative problem solving. Studies in Health Technology and Informatics, Amsterdam, v. 144, p. 193-197, 2009.

TABER, N. Emergency response: Elearning for paramedics and firefighters. Simulation \& Gaming, Newbury Park, Calif., no. 39, p. 515-527, 2008.

VIRVOU, M. Mobile authoring and management of educational software applications: usefulness and usability for teachers. In: CANTONI, L.; MCLAUGHLIN (Ed.). Proceedings of ED-MEDIA 2004. Lugano, Switzerland: [s.n.], 2004. P. 5212-5217.

WILLIAMS, M. et al. Children and emerging wireless technologies: Investigating the potential for spatial practice. In: SIGCHI CONFERENCE ON HUMAN FACTORS IN COMPUTING SYSTEMS, 2005, Portland, Oregon. Proceedings. Portland: ACM Press, 2005. P. 819-828.

WILLS, S. Wireless, mobile \& handheld: Where are our teachers and students going with their computers? EDUCAUSE, Gold Coast, may 2001. 1 CD-ROM.

WINOGRAD, T.; FLORES, F. Hacia la comprensión de la informática y la cognición. Barcelona: Hispano Europea, 1989.

Recebido em maio de 2011.

Aprovado para publicação em julho de 2011.

\section{Jaime Sánchez}

Departamento de Ciencias de la Computación y Centro de Investigación Avanzada en Educación (CIAE), Universidad de Chile - UCHILE, Santiago, Chile. E-mail: jsanchez@dcc.uchile.cl

\section{Matías Espinoza}

Departamento de Ciencias de la Computación y Centro de Investigación Avanzada en Educación (CIAE), Universidad de Chile - UCHILE, Santiago, Chile. E-mail: maespino@dcc.uchile.cl 